\title{
Noncoding RNAs regulate alternative splicing in Cancer
}

\author{
Yunze Liu ${ }^{1,2+}$, Xin Liu ${ }^{3+}$, Changwei Lin ${ }^{4}$, Xianhong Jia $^{2}$, Hongmei Zhu ${ }^{2}$, Jun Song ${ }^{1 *}$ and Yi Zhang ${ }^{1 *}$
}

\begin{abstract}
AS (alternative splicing) is a fundamental process by which a gene can generate multiple distinct mRNA transcripts to increase protein diversity. Defects in AS influence the occurrence and development of many diseases, including cancers, and are frequently found to participate in various aspects of cancer biology, such as promoting invasion, metastasis, apoptosis resistance and drug resistance. NcRNAs (noncoding RNAs) are an abundant class of RNAs that do not encode proteins. NcRNAs include miRNAs (microRNAs), IncRNAs (long noncoding RNAs), circRNAs (circular RNAs) and snRNAs (small nuclear RNAs) and have been proven to act as regulatory molecules that mediate cancer processes through AS. NcRNAs can directly or indirectly influence a plethora of molecular targets to regulate cis-acting elements, trans-acting factors, or pre-mRNA transcription at multiple levels, affecting the AS process and generating alternatively spliced isoforms. Consequently, ncRNA-mediated AS outcomes affect multiple cellular signaling pathways that promote or suppress cancer progression. In this review, we summarize the current mechanisms by which ncRNAs regulate AS in cancers and discuss their potential clinical applications as biomarkers and therapeutic targets.
\end{abstract}

Keywords: Alternative splicing, Cancer, Noncoding RNA, miRNA, IncRNA, circRNA, snRNA

\section{Background}

AS (alternative splicing) of RNA involves the way in which pre-mRNA (pre-messenger RNA) undergoes splicing at different splice sites, and introns are selectively removed while exons are retained to produce two or more kinds of mRNA splicing isoforms. AS progression has been discovered in over $95 \%$ of human multiexon genes and has profound consequences at the protein level, increasing the diversity of gene phenotypes and protein functions in eukaryotes $[1,2]$. AS allows pointed splicing isoforms expressed at a given time to participate in various cellular activities, while AS defects are related to various diseases. In recent decades, it has been observed that many AS changes play vital roles in cancer progression. Cancer cells subvert normal AS events to produce special splicing isoforms that affect cellular

\footnotetext{
*Correspondence: csuzhy@aliyun.com; songjunwk@126.com

${ }^{\dagger}$ Yunze Liu and Xin Liu contributed equally to this work.

'Department of General Surgery, Affiliated Hospital of Xuzhou Medical University, Xuzhou 221000, China

Full list of author information is available at the end of the article
}

functions and potentially control cell proliferation and tumorigenesis. Gaining an understanding of AS mechanisms may reveal new opportunities to develop targeted cancer treatment strategies [3-5].

AS is a highly controlled process, and with the use of high-throughput sequencing and RNA-seq technologies, thousands of ncRNAs (noncoding RNAs) have been identified crucial to regulate AS at multiple levels in cancers [6]. Here, we review our current knowledge of ncRNAs as AS regulators, their mechanisms of action in cancer, and their contributions to the diagnosis and treatment of cancer.

\section{Alternative splicing in cancer}

AS relies mainly on the spliceosome, splice site, cisacting element and trans-acting factor. The spliceosome is assembled from five snRNPs (small nuclear ribonucleoproteins), namely, U1, U2, U4, U5, U6 and over 300 non-snRNP proteins. In AS, spliceosomes recognize splice sites located at the borders between introns and 
exons, including $5^{\prime}$ splice sites, $3^{\prime}$ splice sites and branch points of pre-mRNA. Through recognition, spliceosomes convene and function as ribozymes to catalyze the removal of introns [7]. Then, retained exons link together to eventually generate the mRNA, forming five different types of AS: ES (exon skipping), IR (intron retention), MXE (mutually exclusive exon), A5SS (alternative 5' splice site) and A3SS (alternative 3' splice site) (Fig. 1). During the AS process, the spliceosome cannot interact with the splice site independently to determine the gene sequences of the pre-mRNA that are retained or skipped. Cis-acting elements and trans-acting factors are needed in the recognition and selection of splice sites and in the aggregation of spliceosomes [8].

Cis-acting elements, categorized as ISEs (intron splicing enhancers) and ISSs (silencers), as well as ESEs (exon splicing enhancers) and ESSs (silencers), are the only positions beside variable exons and side-by-side introns to provide gene sites of binding with trans-acting factors [9] (Fig. 2).

Trans-acting factors in AS are mainly SFs (splicing factors), which include three common types [10]: SR (serine/arginine-rich) proteins, hnRNPs (heterogeneous nuclear ribonucleoproteins) and tissue-specific SFs. SR proteins, composed of 12 members (serine/arginine-rich splicing factor 1-12, SRSF1-12), generally bind ESE sequences and promote the recognition of exons by recruiting $\mathrm{U} 1$ to the $5^{\prime}$ splice site and U2AF (U2 auxiliary factor) and U2 to the $3^{\prime}$ splice site $[11,12]$. HnRNPs mainly bind ESS or ISS sequences and inhibit the recognition of exons by hindering contact between spliceosomes and splice sites [13]. Tissue-specific SFs, such as RBM5 (RNA binding motif protein 5), RBM24, QKI (quaking), and Nova1 (NOVA alternative splicing regulator 1), exist in special tissues and allow more specific controls of splice site selection for cell specification and organ function. For example, RBM24 binds an ISE to promote muscle-specific exon inclusion in cardiac and skeletal muscles [14]. In addition to the above three classical SFs, some other regulatory proteins, such as U2AF65, SF3B3 (splicing factor 3b subunit 3), and SF1, have also been classified as SFs by binding directly to pre-mRNAs.

In addition to cis-elements and trans-acting factors, as the excision of most introns occurs cotranscriptionally, AS is coupled with pre-mRNA transcription $[15,16]$. Factors or chromatin modifications related to premRNA transcription are able to affect AS. For instance, a fast rate of Pol II (RNA polymerase II) elongation, which contributes to transcription elongation, induces spliceosome aggregation at the stronger alternative 3' splice site (A3SS), which is located downstream of the weaker A3SS, leading to exon skipping [10]. Moreover, the chromatin modification H3K36me3 (trimethylation on histone $\mathrm{H} 3$ thirty-sixth lysine), which can promote transcriptional activation, results in the recruitment of the SF SRSF1 to pre-mRNA to regulate AS [17].

In cancers, AS defects have been repeatedly observed and result from mutations in genes that encode cis-acting elements [18] or SFs [19] or from misregulations in the AS machinery $[5,20]$. For example, in hematologic malignancies, a gene mutation in the SF SRSF2, which regulates

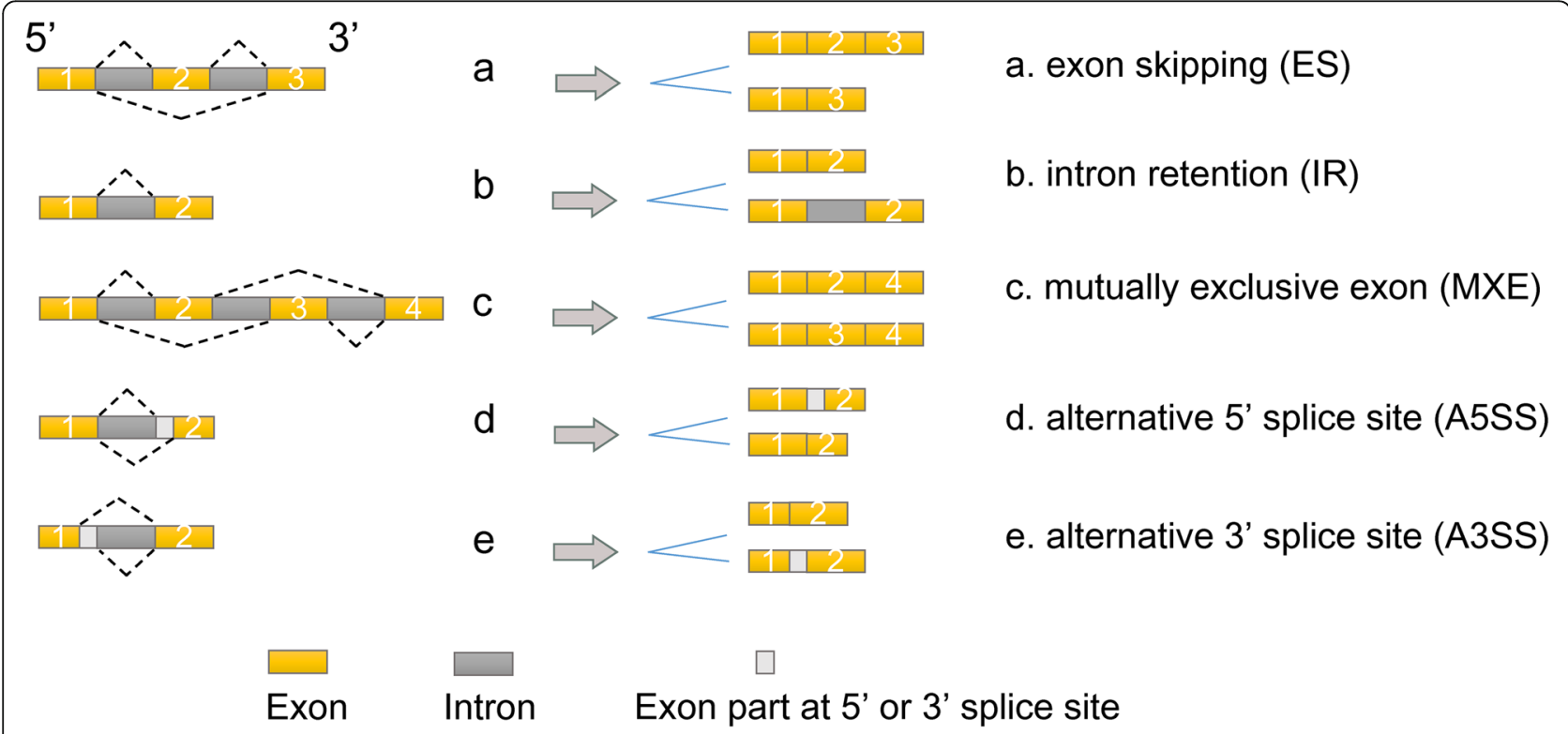

Fig. 1 Different types of AS. a. ES (exon skipping); b. IR (intron retention); c. MXE (mutually exclusive exon); d. A5SS (alternative 5' splice site); and e. A3SS (alternative 3' splice site) 


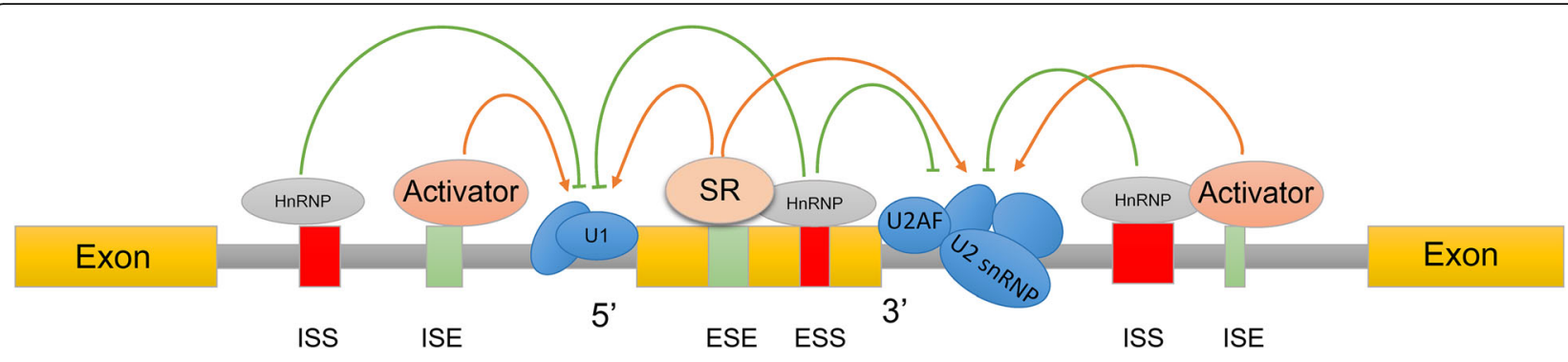

Fig. 2 A schematic representation of AS regulated by cis-acting elements and trans-acting factors. The cis-acting elements ESEs and ESSs represent exonic splicing enhancers and silencers, respectively. ISEs and ISSs represent intronic splicing enhancers and silencers, respectively. SR proteins, hnRNPs, or other transacting factors bind to cis-acting elements for positive or negative AS regulation by affecting the recruitment or recognition of spliceosome components to splice sites; for example, U1 binds to the $5^{\prime}$ splice site, while U2AF and U2 bind to the $3^{\prime}$ splice site

the AS of the EZH2 pre-mRNA, triggers a reduction in $\mathrm{EZH} 2$ isoform expression [21]. In CRC (colorectal cancer) samples, overexpression of the SF SRSF6, which binds to the ZO-1 motif in exon 23, can contribute to the expression of an alternative isoform of ZO-1 due to exon 23 skipping [22].

The outcome of aberrant AS brings numerous special splicing isoforms at the protein level and gives rise to the initiation and progression of cancer. In $\mathrm{PCa}$ (prostate cancer), abnormal splicing of the androgen receptor premRNA produces splicing isoforms that promote drug resistance and cancer aggression [23]. In human skin cancer, a splicing alteration in the protein TNC (tenascin C) pre-mRNA increases the number of tumor-promoting TNC-FL isoforms, resulting in cancer cell invasion and metastasis [24].

\section{Noncoding RNAs in alternative splicing}

NcRNAs, which occupy almost $60 \%$ of the transcriptional output in human cells [25], are RNAs that do not encode proteins. With the development of sequencing technologies, a multitude of ncRNAs have been discovered and classified based on their size or function into many kinds, including miRNAs (microRNAs), siRNAs (small interfering RNAs), piRNAs (piwi-interacting RNAs), rRNAs (ribosomal RNAs), snRNAs (small nuclear RNAs), lncRNAs (long noncoding RNAs), or circRNAs (circular RNAs).

MiRNAs are small ncRNAs that are approximately 19-25 nucleotides in length with highly conserved properties [26]. MiRNA is commonly assembled into the RISC (RNA-induced silencing complex), which is guided to degrade mRNA or simply inhibit mRNA translation without changing mRNA levels, depending on the complete or partial complementation of miRNA. The miRNA-mediated action occurs mainly in the 3' UTR (untranslated region) and sometimes in the 5'UTR of the target mRNA [27-30]. Moreover, some miRNAs are able to stabilize mRNAs or promote translation by binding to the mRNA 5'UTRs [31].

LncRNAs are more than 200 nucleotides in length with poorly conserved properties, and their functions include acting as molecular scaffolds in various biological processes, disturbing nearby pre-mRNA transcription, forming RNA-RNA duplexes with pre-mRNA molecules or miRNAs as posttranscriptional regulators, promoting specific protein activities, and recruiting or inhibiting regulatory proteins in multifarious transcriptional, posttranscriptional or posttranslational manners. Additionally, several lncRNAs encode peptides or generate small RNA molecules that exert biological effects [6, 32-34].

CircRNAs are closed endogenous ncRNAs that are more stable than linear RNAs due to their structures, which are covalently closed continuous loops without a 5' cap structure and 3' polyadenylated tail [35]. CircRNAs can sponge miRNAs through base pairing to protect their target mRNAs. Moreover, circRNAs are able to inhibit or recruit specific proteins to function in the regulation of various biological processes, to enhance particular protein functions to facilitate gene transcription, and to serve as protein scaffolds to promote the reaction of enzymes and substrates. Additionally, some circRNAs may have coding potential to produce peptides under certain conditions [36, 37].

SnRNAs (U1 U7) average approximately 150 nucleotides in length with highly conserved properties and participate in various aspects of RNA biogenesis as core components of functional snRNPs [38, 39]. On the one hand, snRNAs associate with proteins to form snRNPs and play snRNP-mediated regulatory roles. On the other hand, snRNAs can form dynamic base pairing interactions between snRNAs and between snRNAs and the pre-mRNA, ensuring the coordination of pre-mRNA processing $[38,40]$.

According to current studies, ncRNAs, especially miRNAs, lncRNAs and circRNAs, play crucial roles in regulating AS. Recently, snRNAs (U1, U2, U4, U5, and U6) 
have also been shown to act as regulators of AS in cancer, in addition to basal factors of the spliceosome [41, 42]. In the following sections, we further discuss the specific regulatory relationships between ncRNAs and AS in cancers.

\section{Regulation of alternative splicing through cis- acting elements}

Some endogenous ncRNAs that act as NATs (natural antisense transcripts), which are RNAs that contain sequences complementary to other endogenous RNAs, can specifically interact with cis-acting elements in premRNAs by RNA-RNA base pairing. The interaction between ncRNAs and cis-acting elements can affect the selection of splice sites and/or the recruitment of SFs, thus regulating the expression of alternatively spliced isoforms in cancers. According to the origin of ncRNAs, their interaction with cis-acting elements has a cis-NAT form and a trans-NAT form.

A cis-NAT is transcribed from the opposite strand of a DNA strand at the same locus and usually has long perfect complementary sequences with the opposite transcript [43]. One example of a cis-NAT is the IncRNA Saf, which is transcribed from the opposite strand of the genomic DNA sequence of the Fas protein. Saf directly binds to the cis-acting element in the Fas pre-mRNA, and they form a specific doublestranded RNA intermediate located within or surrounded by the alternatively spliced exon 6, consequently recruiting the SF SPF45 to the Fas premRNA. The interaction of Fas pre-mRNA, Saf, and SPF45 stimulates the exon skipping of Fas exon 6, resulting in the expression of the sFas (soluble Fas) isoform [44], which contributes to cancer survival by inhibiting Fas-mediated apoptosis in multiple cancers [45] (Fig. 3a). Another example of a cis-NAT is the lncRNA EGOT, which is transcribed from the opposite strand of the ITPR1 (inositol 1,4,5-trisphosphate receptor type 1) genomic sequence. EGOT can directly bind to the cis-acting element in ITPR 1 premRNA, resulting in the recruitment of the SF hnRNPH1 to promote hnRNPH1-mediated AS, contributing to the expression of the ITPR1 protein, which sensitizes cells to paclitaxel cytotoxicity in cancer therapy [46]. Additionally, the lncRNA Zeb2 is a NAT and is transcribed from the opposite strand of the Zeb2 protein genomic sequence, binds to the cisacting element in Zeb2 pre-mRNA and overlaps the splice site in the 5'UTR intron, preventing recognition of the spliceosome. The interaction between the Zeb2 NAT and Zeb2 pre-mRNA promotes the inclusion of the 5'UTR intron, thus increasing the levels of the Zeb2 protein, which can activate EMT (epithelialmesenchymal transition) in breast cancer cells [47].
In contrast, ncRNAs can also interact with cis-acting elements through the trans-NAT form to regulate AS. A trans-NAT is transcribed from different genomic loci and usually has short and imperfect complementarity with the target pre-mRNA [43]. For example, the lncRNA BC200, derived from the BC200 gene, can directly bind the cis-acting element in the Bcl-x pre-mRNA derived from the $\mathrm{Bcl}-\mathrm{x}$ gene [48, 49]. The lncRNA BC200 forms a specific double-stranded RNA intermediate with $\mathrm{Bcl}-\mathrm{x}$ pre-mRNA exon 3, promoting the recruitment of the SF hnRNPA2/B1 to Bcl-x pre-mRNA. The interaction among $\mathrm{BC} 200$, hnRNPA2/B1 and Bcl-x premRNA produces the $\mathrm{Bcl}-\mathrm{xL}$ isoform and suppresses the expression of the $\mathrm{Bcl}-\mathrm{xS}$ isoform [50], contributing to the apoptosis resistance of breast tumor cells [51] (Fig. $3 \mathrm{~b})$. Additionally, the IncRNA CCAT2, which is transcribed from genomic loci that is different from GLS (glutaminase), binds to an intron 14 fragment of GLS pre-mRNA and recruits the CFIm (cleavage factor I) complex to GLS pre-mRNA by direct binding. The CCAT2-CFIm-GLS interaction results in the expression of the GAC (glutaminase C) splicing isoform, promoting metastases and cell proliferation in CRC [52]. Moreover, the snRNA U1, which recognizes transcriptome-wide 5' splice sites through base pairing [53], can bind to extensive U1-targeted pre-mRNAs to promote intron exclusion. Aberrant U1-mediated AS events generate many kinds of splicing isoforms and have a close association with characteristic breast cancer subtypes [41].

Therefore, some ncRNAs are able to interact with cisacting elements through the cis-NAT or trans-NAT form, impacting AS outcomes in cancers.

\section{Regulation of alternative splicing through trans- acting factors \\ Posttranscriptional regulation of splicing factors}

NcRNAs have been observed as posttranscriptional regulators that participate in the regulation of the mRNA expression of SFs, thereby affecting splicing isoform outcomes.

MiRNAs can inhibit SF expression through complete or partial complementation with the target mRNA of an $\mathrm{SF}$, degradation of the mRNA or the downregulation of mRNA translation as a result $[54,55]$ (Fig. 4a). For example, in neuroblastoma, both miR-10a and miR-10b degrade SRSF1 mRNA through complete complementation with its 3'UTR and downregulate the translation of SRSF1 as a result of decreasing SRSF1-mediated AS, thus inhibiting the migration, invasion, and metastasis of neuroblastoma cells [56]. Additionally, miR-30c in PCa cells degrades SRSF1 mRNA through complete complementation with its 3'UTR and downregulates its translation to decrease SRSF1-mediated AS, thus suppressing PCa cell survival [57]. Moreover, in HCC (hepatocellular 


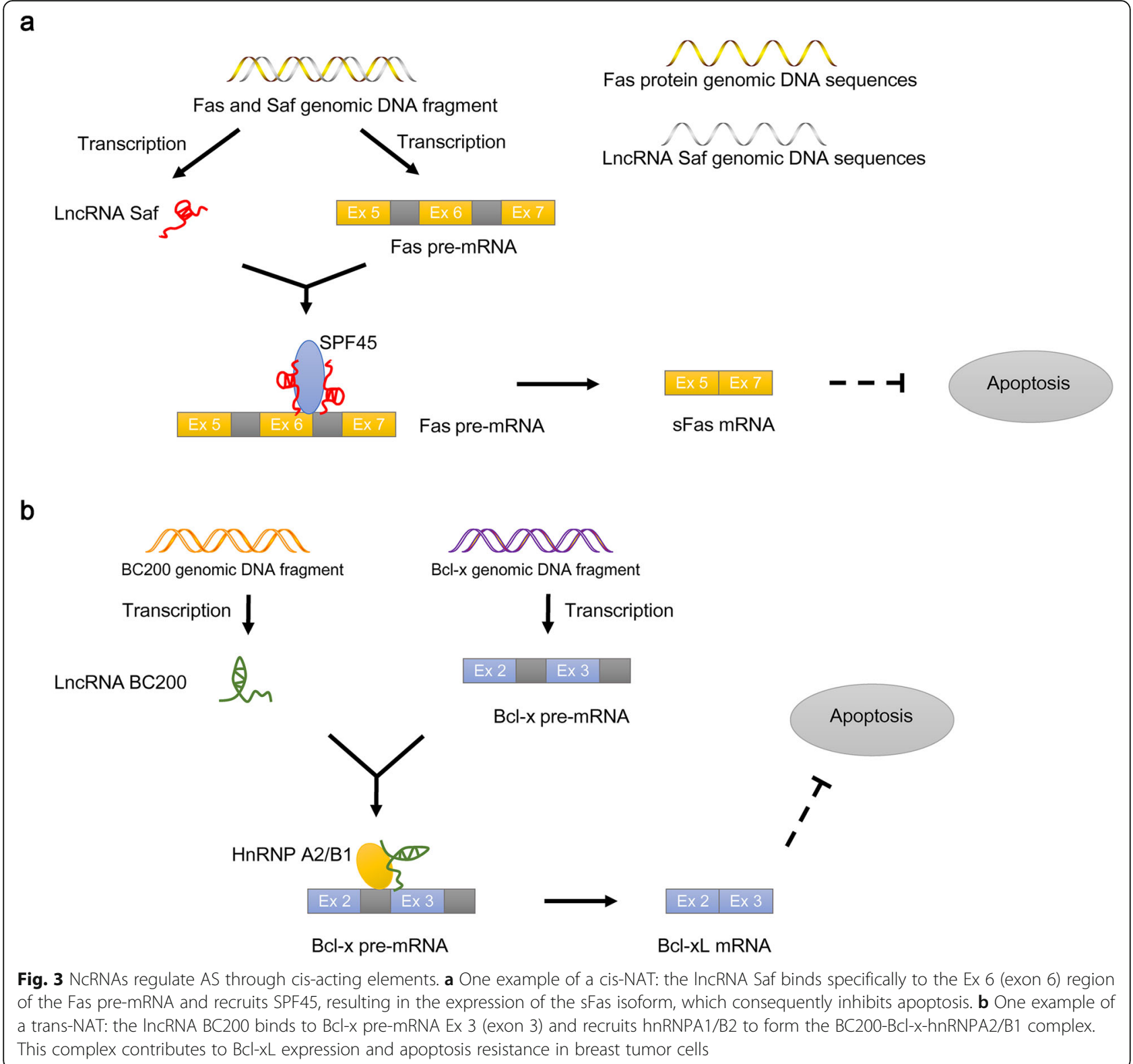

carcinoma), miRNA-133b inhibits the translation of SF3B4 (splicing factor 3b subunit 4) mRNA through partial complementation with its 3'UTR to decrease SF3B4mediated AS, repressing cell proliferation and metastasis [58]. In HeLa cells, miR-7 inhibits the mRNA translation of the SF SRSF1 through partial complementation with its 3'UTR to downregulate SRSF1-mediated AS, suppressing cancer cell survival [59]. Here, we summarize the current miRNAs that regulate SFs at the posttranscriptional level Table 1.

Some miRNAs and SFs form modulatory feedback circuits to maintain the coordination and relationship between miRNA-mediated SF gene repression and miRNA expression in AS regulatory networks.
For instance, miR-7 prevents the translation of SRSF1 mRNA and decreases SRSF1-mediated AS, repressing cancer cell survival. In turn, SRSF1 directly binds to the long primary transcript of miR-7 called pri-miR-7, and SRSF1-independent splicing promotes pri-miR-7 processing into miR-7 by facilitating cleavage by Drosha [59]. Additionally, miR181a-5p directly decreases both SRSF7 mRNA and protein levels, downregulating SRSF7-mediated AS, which reduces renal cancer cell proliferation. Conversely, SRSF7 contributes to miR-181a-5p expression through a possible mechanism that directly facilitates maturation of the miR-181a-5 primary transcript [62]. 


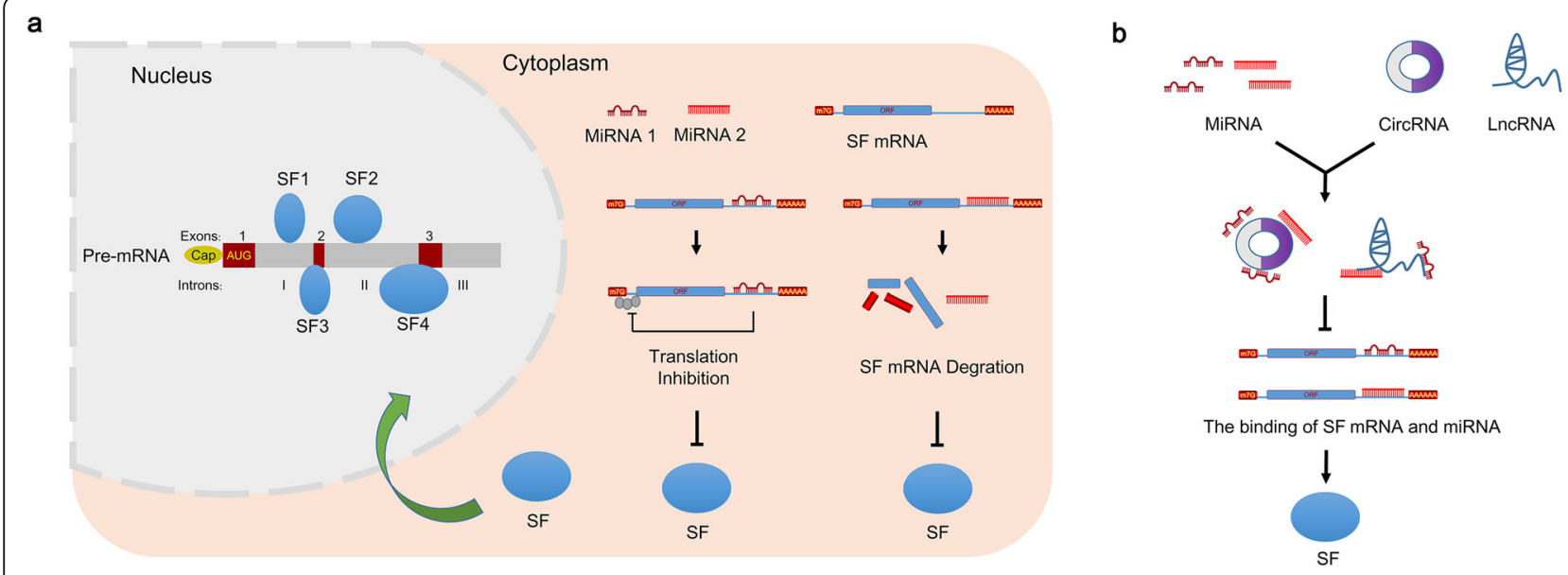

Fig. 4 NCRNAs regulate AS through the posttranscriptional regulation of SFs. a MiRNAs silence SFs by directly binding to the SF mRNA. b CircRNAs and IncRNAs can sponge miRNA functions by directly binding to block their function with SF mRNAs, promoting SF expression

Table 1 MiRNAs that regulate SFs at the posttranscriptional level

\begin{tabular}{|c|c|c|c|}
\hline MiRNA & Splicing factor & Cancer & Reference \\
\hline $\begin{array}{l}\text { MiR-10a, miR-10b, miR-10b-5p, miR- } \\
\text { 203a-3p, miR30c }\end{array}$ & SRSF1 & Neuroblastoma, renal cancer, prostate cancer & $\begin{array}{l}{[56]} \\
{[57],[60]}\end{array}$ \\
\hline MiR-193a-3p, miR-200c-3p, miR-183-5p & SRSF2 & Gastric cancer, renal cancer & {$[60],[61]$} \\
\hline MiR-193a-5p & SRSF6 & Pancreatic cancer & {$[61]$} \\
\hline $\begin{array}{l}\text { MiR-30a-5p, miR-216b-5p, miR-181a-5p, } \\
\text { miR-7 }\end{array}$ & SRSF7 & Renal cancer, cervical cancer & [59], [62] \\
\hline MiR-1 & SRSF9 & Bladder cancer & [63] \\
\hline $\begin{array}{l}\text { MiR-374b, miR-490, miR-149-5p, miR- } \\
\text { 135a-5p, miR-137 }\end{array}$ & HnRNPA1 & Hepatocellular carcinoma, gastric cancer, renal cancer & $\begin{array}{l}{[64],[60],} \\
{[65],[66]}\end{array}$ \\
\hline MiR-124, miR-340 & HnRNPA2 & Colorectal cancer & {$[65]$} \\
\hline MiR-335 & $\operatorname{Tra} 2 \beta$ & Lung cancer & {$[67]$} \\
\hline MiR-938 & RBM5 & Lung adenocarcinoma & {$[68]$} \\
\hline MiR-335 & RBM10 & Endometrial cancer & {$[69]$} \\
\hline MiR-137, miR-340, miR-133b, miR-124 & PTBP1 & Gastric cancer, colorectal cancer & [65], [70] \\
\hline MiR-10b & $\begin{array}{l}\text { MBNL1, MBNL2, } \\
\text { DGCR14 }\end{array}$ & Intracranial glioblastoma & {$[71]$} \\
\hline MiR-200, miR-221, miR-375 & QKI & $\begin{array}{l}\text { Colorectal cancer, lung adenocarcinoma, oral squamous cell carcinoma, } \\
\text { head and neck squamous cell carcinoma, breast cancer, prostate cancer }\end{array}$ & [72], [73], [74] \\
\hline MiR-27a-3p & NOVA1 & Gastric cancer & {$[75]$} \\
\hline MiR-27b-3p & KHSRP & Breast cancer & {$[76]$} \\
\hline MiR-184 & SF1 & Oral squamous cell carcinoma & {$[77]$} \\
\hline MiR-361-3p, miR-615-5p & SF3B3 & Non-small cell lung cancer & [78] \\
\hline MiR-133b & SF3B4 & Hepatocellular carcinoma & {$[58]$} \\
\hline
\end{tabular}


In addition, circRNAs and lncRNAs have been observed to promote SF expression by binding and sponging miRNAs as ceRNAs (competing endogenous RNAs), thus regulating AS in cancers (Fig. $4 \mathrm{~b}$ ). For example, in non-small cell lung cancer, the circRNA 100,146 can bind and sponge miR-361-3p and miR-615-5p, which both directly inhibit the expression of the SF SF3B3, thus increasing SF3B3mediated AS to promote the proliferation and invasion of cancer cells [78]. Similarly, the IncRNA UCA1 can bind and sponge miR-184, which directly decreases the expression of SF1, resulting in the upregulation of SF1-mediated AS to accelerate the proliferation and cisplatin resistance of oral squamous cell carcinoma [77]. The lncRNA CCAT1 binds and sponges miR-490, which directly inhibits the expression of the SF hnRNPA1, consequently increasing hnRNPA1-mediated AS to promote gastric cancer cell migration [64].

\section{Posttranslational regulation of splicing factors}

Acting as posttranslational regulators of SFs, ncRNAs can control the posttranslational chemical modifications (e.g., phosphorylation) of SFs or decoy SFs, remodel chromatin, or encode peptides to interact with SFs, thus altering splicing outcomes in cancers.

\section{Posttranslational chemical modifications}

NcRNAs are able to control SF phosphorylation, which enhances SF activity to promote AS. In CRC cells, the IncRNA MALAT1 has been found to form a complex with both SRSF1 and SRPK1 (serine/arginine protein kinase 1) in nuclear speckles [79]. MALAT1 can increase both the expression and activity of SRPK1 [80], which functions to catalyze SRSF1 phosphorylation by binding to the RS domain of unphosphorylated SRSF1 [81]. MALAT1-mediated SRSF1 phosphorylation can affect the subcellular localization of SRSF1 and promote splice site selection in AKAP-9 (A-kinase anchor protein 9) pre-mRNA [82-84], thus contributing to the expression of the AKAP-9 isoform, which exacerbates cellular proliferation, migration and invasion in CRC [80] (Fig. 5a).

\section{Decoy splicing factors}

Some ncRNAs can act as "decoys" to inhibit SFs binding to targeted pre-mRNAs through direct interactions, thus

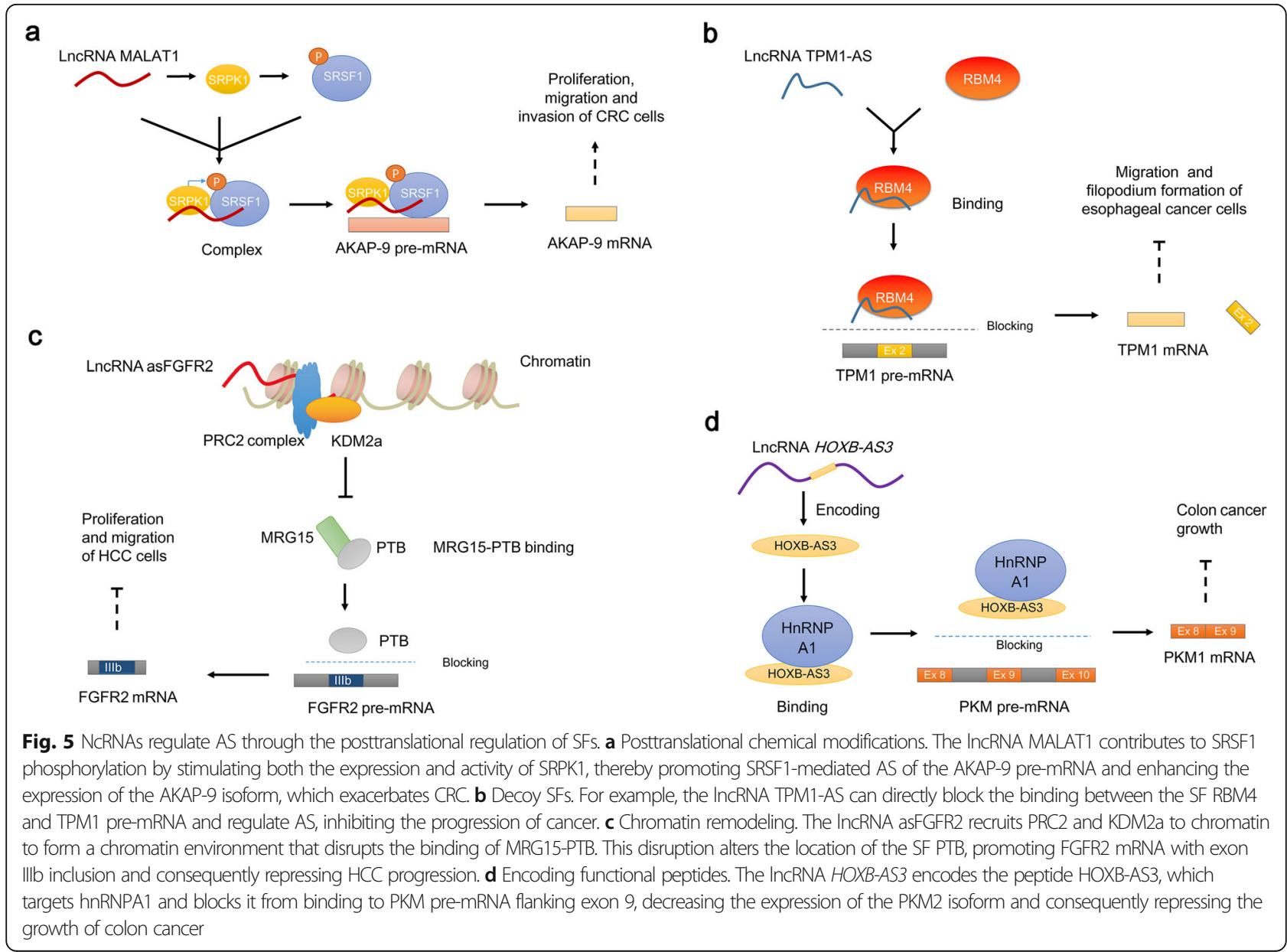


regulating AS in cancers [85-87]. For example, the lncRNA TPM1-AS binds to the SF RBM4 and blocks the targeting of TPM1 pre-mRNA, leading to the inhibiting of TPM1 exon 2a inclusion and a decrease in the two tumorigenic splicing isoforms V2 and V7 and thus inhibiting migration and filopodium formation in esophageal cancer cells [88] (Fig. 5b). Additionally, the lncRNA PNCTR can recruit at least 6 of the SF PTBP1 (polypyrimidine tract binding protein 1) molecules and sequester them in a nuclear body called the PNC (perinucleolar compartment), hindering PTBP1 from acting on CHEK2 (checkpoint kinase 2) pre-mRNA and contributing to the expression of a CHEK2 isoform that includes exon 8. The lncRNA PNCT $\mathrm{R}$-mediated splicing isoform promotes cell survival in many kinds of cancers [89]. Moreover, the circRNA circSMARCA5 binds and decoys the SF SRSF1 away from VEGF-Axxxa pre-mRNA to decrease the expression of the proangiogenic splicing isoform VEGF-Axxxa, repressing cancer progression in glioblastoma multiforme [90]. Additionally, the circRNA circ-UBR5 can recruit the SFs QKI and NOVA1 and block their splicing functions to change the AS outcome, affecting tumor differentiation in non-small cell lung cancer [91]. It should be noted that a series of studies on the decoy roles by which ncRNAs inhibit SF-mediated AS in cancers have been conducted Table 2 . In addition to the inhibitory function described above, ncRNAs can also act as "decoys" to promote the binding of SFs to targeted pre-mRNAs. For example, the lncRNA PCGE M1 can bind and enhance the binding capacity of the SF U2AF65 to AR pre-mRNA and promote the expression of the AR3 splicing isoform by exonization, contributing to the development of PCa $[87,100]$.

\section{Chromatin remodeling}

NcRNAs can fine-tune the chromatin structure, which controls the recruitment of SFs to affect their interaction with pre-mRNAs in the AS process, changing splicing outcomes. The lncRNA asFGFR2 has been verified to function through the recruitment of PRC2 (polycomb repressive complex 2, one of the two classes of polycombgroup proteins) and the histone demethylase KDM2a (lysine-specific demethylase $2 \mathrm{~A}$ ) to chromatin to form a special chromatin environment that disrupts the binding between MRG15 (MORF4-related gene on chromosome 15) with PTB (polypyrimidine tract binding protein). The disruption of the MRG15-PTB interaction alters the location of the SF PTB and decreases the recruitment of the SF PTB to exon IIIb, promoting exon IIIb inclusion in the course of FGFR2 (fibroblast growth factor receptor 2) splicing [101] and consequently producing the FGFR2-IIIb isoform, which decreases the proliferation and migratory potential of HCC [102] (Fig. 5c).

\section{Encoding functional peptides}

NcRNAs, especially lncRNAs, are able to regulate SFs at the posttranslational level through limited coding potential. For example, the lncRNA HOXB-AS3 encodes a conserved HOXB-AS3 peptide, and the HOXB-AS3 peptide competitively targets arginine residues in an RNAbinding area (called an RGG box) of hnRNPA1, which blocks the binding of hnRNPA1 to certain sequences of the PKM (pyruvate kinase $M$ ) pre-mRNA flanking exon 9, thereby inhibiting hnRNPA1-mediated AS, decreasing the expression of the PKM2 isoform and consequently repressing the growth of colon cancer [103] (Fig. 5d).

\section{Regulation of alternative splicing through pre- mRNA transcription}

AS is not an independent posttranscriptional regulation but is intimately coupled with transcription, and factors that regulate pre-mRNA transcription can have an impact on AS [10]. Emerging roles of ncRNAs have been found to directly participate in transcription [31, 104,

Table 2 NcRNAs as SF decoys to inhibit SF-mediated AS in cancer

\begin{tabular}{llll}
\hline NcRNA & Splicing factor & Cancer & Reference \\
\hline CircSMARCA5 & SRSF1 & Glioblastoma multiforme & [90] \\
LINC01133 & SRSF6 & Colorectal cancer & [92] \\
PCGEM1 & HnRNPA1 & Prostate cancer & [87] \\
TPM1-AS & RBM4 & Esophageal cancer & {$[88]$} \\
FAS-AS1 & RBM5 & B-cell lymphomas & [93] \\
PNCTR, PANDAR, LUCAT1 & PTBP1 & Cervical cancer, osteosarcoma, colorectal cancer & [89], [94] \\
Circ-UBR5 & & Non-small cell lung cancer & [95] \\
MALAT1 & QKI, NOVA1 & Colorectal cancer & [96] \\
Gomafu & SFPQ & Neuroblastoma & [97] \\
SPry1 & SF1, Celf3 & Breast cancer & [98] \\
LASTR & U2AF65 & Breast cancer & [99] \\
\hline
\end{tabular}


105] and may therefore impact the AS outcome. For example, the lncRNA EZR-AS1 can form a complex with Pol II and recruit the histone H3-lysine 4-specific methyltransferase SMYD3 (SET and MYND domain containing protein 3) to a site downstream of the transcription promoter. The interaction of EZR-AS1 with Pol II and SMYD3 promotes the histone modification H3K4me3 (trimethylation of lysine 4 on histone $\mathrm{H} 3$ ) in transcription sites and facilitates pre-mRNA transcription [106, 107]. H3K4me3 is also able to recruit spliceosome components to promote the exclusion of exon 2 from the MCL1 (myeloid cell leukemia 1) pre-mRNA, resulting in the expression of the MCL1S isoform, which induces cancer cell apoptosis [107-110]. In addition, the lncRNA HOTAIR decreases the recruitment of multiple promoting molecules of SETD2 (SET domain-containing 2, the specific methyltransferase of $\mathrm{H} 3 \mathrm{~K} 36$ ) to downregulate SETD2 expression and phosphorylation, thus reducing SETD2-mediated H3K36me3, which can activate premRNA transcription [111, 112]. The reduction in H3K36me3 promotes the expression of the CDH1 (cadherin 1) isoform with exon 8, acting as a biological marker in gastric cancer occurrence [113]. Furthermore, the lncRNA DACOR1 in colon cancer cells promotes genome-wide DNA methylation [114, 115]. Interestingly, not correlating with the negative regulation of transcription, DNA methylation at Oct4A gene enhancers can facilitate the expression of the Oct4A splicing isoform by affecting the AS of Oct4A pre-mRNA, inhibiting cell aging in embryonal carcinoma $[115,116]$.

In conclusion, ncRNAs may regulate AS by affecting transcription, mainly by interacting with Pol II and regulating histone modification and DNA methylation.

\section{Diagnostic and therapeutic value of ncRNA-regulated alternative splicing in cancer}

High-throughput sequencing technology has allowed the measurement of an AS event in terms of an overall ratio, and the final results make it possible to provide diagnostic information in this manner. An increasing number of studies have indicated that ncRNAs can serve as biomarkers for diagnosis or drug resistance in many types of cancers due to their participation in AS events [61, 64, 117-121]. For example, the lncRNA HOXA11-AS can regulate SF SRSF1-mediated AS, contributing to GC (gastric cancer) cell proliferation and invasion. Expression of the IncRNA HOXA11-AS was found to be increased in GC tissues and serum samples. Clinical data indicate that GC patients with a high HOXA11-AS level have a poor prognosis and that HOXA11-AS may function as a potential diagnostic biomarker in GC [117]. Additionally, the lncRNA $91 \mathrm{H}$ has been verified to regulate hnRNPK-mediated AS, affecting cancer processes such as metastasis in CRC. Expression of the lncRNA
$91 \mathrm{H}$ in the serum was found to be increased in CRC patients and is considered an early clinical marker for CRC recurrence and metastasis [119]. Additionally, the lncRNA LINC01133 can block the splicing function of SRSF6 [92], which contributes to the EMT process by promoting the expression of the tumorigenic splicing isoform [22]. Analyses of clinical CRC tissues have shown that patients with high LINC01133 expression always have better survival outcomes than those with low expression and that LINC01133 may act as a prognostic biomarker due to its antimetastatic function. In addition, miR-193a-3p can downregulate AS events mediated by the SF SRSF2, thereby contributing to cisplatin resistance. Analyses of clinical GC tissues have suggested that some patients with high miR-193a-3p expression may have a high level of resistance to cisplatin and that miR193a-3p may act as a clinical biomarker of cisplatin resistance in GC patients after surgery [122]. Moreover, the lncRNA EGOT participates in the AS of ITPR1 premRNA, sensitizing cancer cells to paclitaxel treatment. Analyses of clinical breast cancer samples have shown that patients with low EGOT expression have a high level of paclitaxel resistance and that EGOT may be utilized as a diagnostic biomarker of paclitaxel treatment for breast cancer patients after surgery [46].

In view of the important regulatory roles in AS, ncRNAs have rapidly emerged as promising targets for pharmaceutical development in cancers $[67,68,92,123-$ 131]. For example, the IncRNA FAS-AS1 promotes the expression of the splicing isoform sFas by directly binding with the SF RBM5, thus increasing resistance to apoptosis in B-cell lymphomas [93]. Ibrutinib has been proven to repress the splicing isoform mediated by RBM5 for cell-killing effects by downregulating FASAS1 expression, and it has been applied to target B-cell malignancies as an anticancer drug [93, 132, 133]. Additionally, miR-424 and miR-503 can regulate AS events mediated by the SF hnRNPA1, decreasing breast cancer cell proliferation [134]. Resveratrol, a polyphenolic phytoalexin with multiple functions, such as antitumorigenic and anti-inflammatory effects $[135,136]$, is a popular health care product on the market. It has been found that resveratrol is able to promote the expression of the tumor-suppressive miRNAs miR-424 and miR503 , and it has been regarded as a promising application for cancer prevention and treatment [134]. Furthermore, with high expression in all GBM (glioblastoma) subtypes, oncogenic miR-10b possesses strong therapeutic potential due to its regulatory function in AS by interacting with multiple SFs, including MBNL1 (muscleblind-like splicing regulator 1), MBNL2 and DGCR14 (DiGeorge syndrome critical region gene 14) [71, 137]. Various formulations of miR-10b ASO (antisense oligonucleotide) inhibitors delayed GBM progression in mouse models 


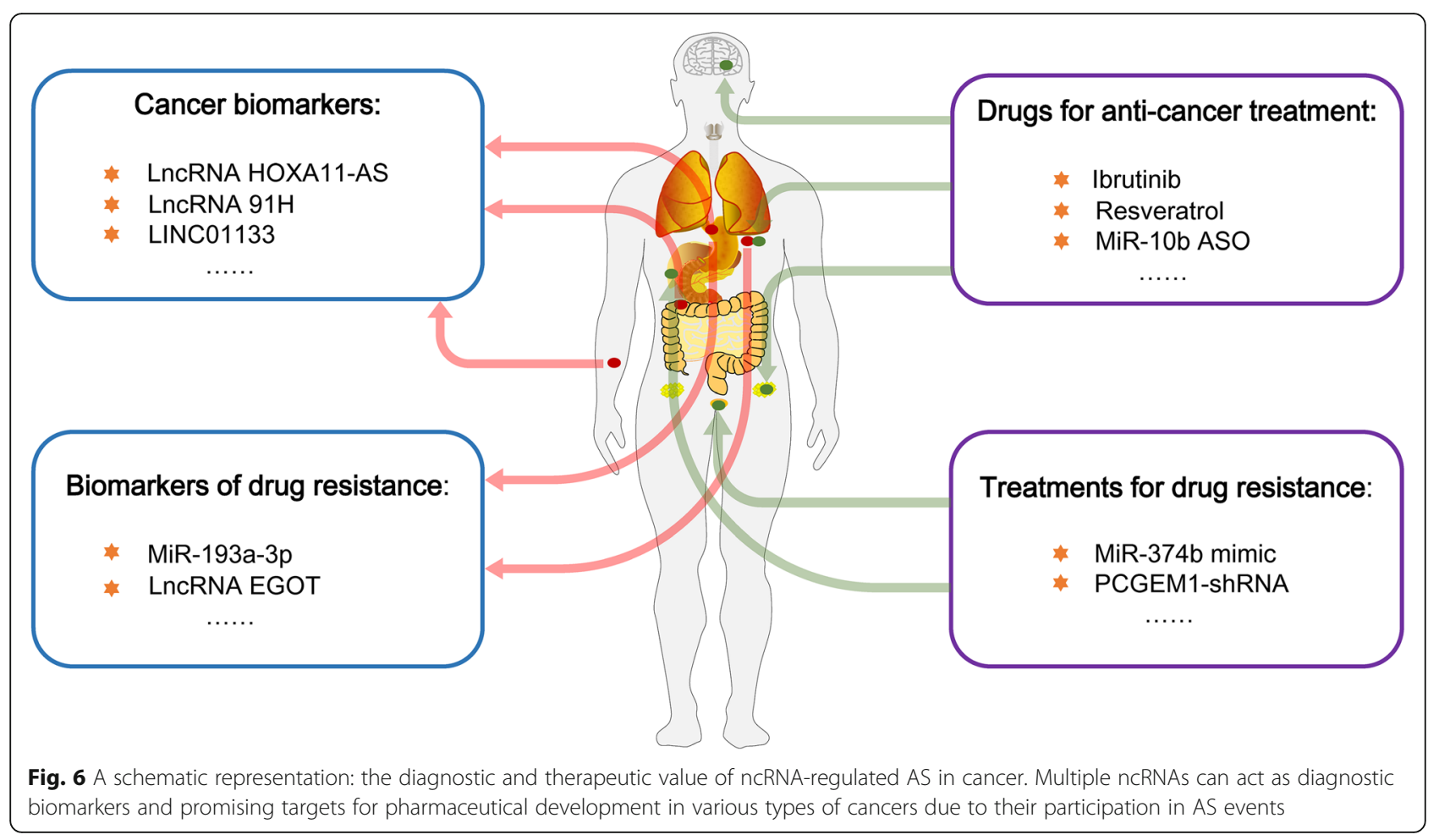

Table 3 LncRNAs that regulate AS in cancer

\begin{tabular}{|c|c|c|c|}
\hline LncRNA & Function & Cancer & Reference \\
\hline Saf & Interaction with Fas pre-mRNA through the cis-NAT form & Leukemia, cervical cancer & [44] \\
\hline EGOT & Interaction with ITPR1 pre-mRNA through the cis-NAT form & Breast cancer & [46] \\
\hline Zeb2 & Interaction with Zeb2 pre-mRNA through the cis-NAT form & Breast cancer & {$[47]$} \\
\hline BC200 & Interaction with Bcl-x pre-mRNA through the trans-NAT form & Breast cancer & {$[50]$} \\
\hline CCAT2 & Interaction with GLS pre-mRNA through the trans-NAT form & Colorectal cancer & {$[52]$} \\
\hline UCA1 & Sponging miR-184-mediated AS & Oral squamous cell carcinoma & [77] \\
\hline CCAT1 & Sponging miR-490-mediated AS & Gastric cancer & [64] \\
\hline MALAT1 & Promoting SRPK1-catalyzed SRSF1 phosphorylation & Colorectal cancer & [80] \\
\hline LINC01133 & Decoying the SF SRSF6 away from the targeted pre-mRNA & Colorectal cancer & [92] \\
\hline PCGEM1 & Decoying the SF HnRNPA1 away from the targeted pre-mRNA & Prostate cancer & [87] \\
\hline TPM1-AS & Decoying the SF RBM4 away from the targeted pre-mRNA & Esophageal cancer & [88] \\
\hline FAS-AS1 & Decoying the SF RBM5 away from the targeted pre-mRNA & B-cell lymphomas & [93] \\
\hline $\begin{array}{l}\text { PNCTR, PANDAR, } \\
\text { LUCAT1 }\end{array}$ & Decoying the SF PTBP1 away from the targeted pre-mRNA & $\begin{array}{l}\text { Cervical cancer osteosarcoma, } \\
\text { colorectal cancer }\end{array}$ & $\begin{array}{l}\text { [89], [94], } \\
{[95]}\end{array}$ \\
\hline MALAT1 & Decoying the SF SFPQ away from the targeted pre-mRNA & Colorectal cancer & [96] \\
\hline Gomafu & Decoying the SF SF1 and Celf3 away from the targeted pre-mRNA & Neuroblastoma & [97] \\
\hline Spry1 & Decoying the SF U2AF65 away from the targeted pre-mRNA & Breast cancer & [98] \\
\hline LASTR & Decoying the SF SART3 away from the targeted pre-mRNA & Breast cancer & [99] \\
\hline asFGFR2 & $\begin{array}{l}\text { Fine-tuning the chromatin structure to decrease the recruitment of } \\
\text { the SF PTB }\end{array}$ & Breast cancer & [101] \\
\hline HOXB-AS3 & Encoding peptides to inhibit hnRNPA1-mediated AS & Colon cancer & [103] \\
\hline
\end{tabular}


through three routes (direct intratumoral injection, continuous osmotic delivery, and systemic intravenous injection) without significant systemic toxicity, indicating that a miR-10b inhibitor can be used as a drug against all GBM subtypes [71]. Moreover, in HCC, miR-374b can play an AS regulatory role in the miR-374b/ hnRNPA1/PKM2 axis, addressing the problem of sorafenib resistance. MiR-374b mimic was transfected by lipofectamine, which was injected into SCID mice sensitized HCC cells to sorafenib toxicity, indicating that miR-374b is an effective treatment for sorafenib resistance [66]. In addition, in prostate cancer, PCGEM1 inhibits HnRNPA1-mediated AS in androgen receptor pre-mRNA, promoting castration resistance (including drug resistance to enzalutamide and abiraterone) [87, 138]. PCGEM1-shRNA, through lentiviral packaging and injection into castrated male SCID mice, restrains tumor growth, suggesting that PCGEM1 can act as a likely drug target of castration resistance [87] (Fig. 6).

\section{Conclusions}

We summarize the recent ncRNAs, mainly miRNAs (Table 1) and lncRNAs (Table 3), that regulate AS at multiple levels in cancer. Notably, current related observations focus mainly on regulation through cis-acting elements or trans-acting factors based on the posttranscription of nascent pre-mRNAs. Considering that a pre-mRNA indicates simply an immature and temporary state (as a presumptive primary transcript) and that the process of transcription is accompanied by splicing, ncRNA-regulated transcription could have a comprehensive and complex impact on AS, including the maturation and selection of cis-acting elements and the recruitment of trans-acting factors. The direct observation of the functions of ncRNAs in transcription and AS is a potential research direction in the AS domain of cancers.

The number of current studies on the association of ncRNAs with the regulation of AS in cancer is limited. In view of the use of new technologies represented by high-throughput sequencing and further experiments with innovative designs, it is predictable that many AS-associated ncRNAs, splicing isoforms and new regulatory mechanisms of cancer progression will be found and may provide potential targets for cancer diagnosis and therapy. Additionally, questions remain in the field of small molecules against ncRNA targets. One key consideration is how to classify and evaluate ncRNA targets, as ncRNA targets usually do not have "active sites" [139]. In addition, ncRNA therapeutics may need solutions for drug delivery, toxic side effects, and drug resistance [140, 141].

\section{Abbreviations}

AS: Alternative splicing; ncRNA: Noncoding RNA; pre-mRNA: Pre-messenger RNA; snRNPs: Small nuclear ribonucleoprotein; ISE: Intron splicing enhancer;
ISS: Intron splicing silencer; ESE: Exon splicing enhancer; ESS: Exon splicing silencer; ES: Exon skipping; IR: Intron retention; MXE: Mutually exclusive exon; A5SS: Alternative 5' splice site; A3SS: Alternative 3' splice site; SF: Splicing factor; SR: Serine/arginine-rich; hnRNP: Ribonucleoprotein; RBM5: RNA binding motif protein 5; RBM24: RNA binding motif protein 24; QKI: Quaking; Nova1: NOVA alternative splicing regulator 1; SRSF1-12: Serine/arginine-rich splicing factor 1-12; U2AF: U2 auxiliary factor; SF3B3: Splicing factor 3b subunit 3; Pol II: RNA polymerase II; H3K36me3: Trimethylation on histone H3 thirty-sixth lysine; CRC: Colorectal cancer; PCa: Prostate cancer; TNC: Tenascin C; miRNA: MicroRNA; siRNA: Small interfering RNA; piRNA: Piwi-interacting RNA; rRNA: Ribosomal RNA; snRNA: Small nuclear RNA; IncRNA: Long noncoding RNA; circRNA: Circular RNA; RISC: RNA-induced silencing complex; UTR: Untranslated region; NAT: Natural antisense transcript; sFas: Soluble Fas; ITPR1: Inositol 1,4,5-trisphosphate receptor type 1; EMT: Epithelialmesenchymal transition; GLS: Glutaminase; CFIm: Cleavage factor I; GAC: Glutaminase C; Ex: Exon; HCC: Hepatocellular carcinoma; SF3B4: Splicing factor 3b subunit 4; ceRNA: Competing endogenous RNA; SRPK1: Serine/ arginine protein kinase 1; AKAP-9: A-kinase anchor protein 9; PTBP1: Polypyrimidine tract binding protein 1; PNC: Perinucleolar compartment; CHEK2: Checkpoint kinase 2; PRC2: Polycomb repressive complex 2; KDM2a: Lysine-specific demethylase 2A; MRG15: MORF4-related gene on chromosome 15; PTB: Polypyrimidine tract binding protein; FGFR2: Fibroblast growth factor receptor 2; PKM: Pyruvate kinase M; SMYD3: SET and MYND domain containing protein 3;

H3K4me3: Trimethylation of lysine 4 on histone H3; MCL1: Myeloid cell leukemia 1; SETD2: SET domain-containing 2; CDH1: Cadherin 1; GC: Gastric cancer; GBM: Glioblastoma; MBNL1: Muscleblind like splicing regulator 1; DGCR14: DiGeorge syndrome critical region gene 14; ASO: Antisense oligonucleotide

\section{Acknowledgements}

Not applicable.

\section{Authors' contributions}

$Y Z, C W L$ and $Y Z L$ designed the research. YZL drafted the manuscript. XL improved the structure of this manuscript and completed the diagrams. $Y Z$, JS, $\mathrm{XHJ}$ and HMZ discussed and revised the manuscript. JS put forward some constructive suggestions. All authors read and approved the final manuscript.

\section{Funding}

This research was supported in part by the National Natural Science Foundation of China (Nos. 81702435; Nos. 82072729), the Natural Science Foundation of Jiangsu (BK20170264) and Xuzhou Key R\&D Program (KC20064).

Availability of data and materials

All data generated or analyzed during this study are included in this published article.

Ethics approval and consent to participate

Not applicable.

\section{Consent for publication}

All of the authors are aware of and agree to the content of the paper and their being listed as a co-author of the paper.

\section{Competing interests}

The authors declare that they have no competing interests.

\section{Author details}

${ }^{1}$ Department of General Surgery, Affiliated Hospital of Xuzhou Medical University, Xuzhou 221000, China. ${ }^{2}$ Department of Traditional Chinese Medicine, Affiliated Hospital of Xuzhou Medical University, Xuzhou 221000, China. ${ }^{3}$ Department of Endocrinology, Affiliated Hospital of Xuzhou Medical University, Xuzhou 221000, China. ${ }^{4}$ Department of Gastrointestinal Surgery, the Third XiangYa Hospital of Central South University, Changsha 410013, China. 


\section{Received: 18 September 2020 Accepted: 3 December 2020}

\section{Published online: 06 January 2021}

\section{References}

1. Keren H, Lev-Maor G, Ast G. Alternative splicing and evolution: diversification, exon definition and function. Nat Rev Genet. 2010;11(5):345-55.

2. Yang X, Coulombe-Huntington J, Kang S, Sheynkman GM, Hao T, Richardson A, et al. Widespread expansion of protein interaction capabilities by alternative splicing. Cell. 2016;164(4):805-17.

3. Frampton GM, Ali SM, Rosenzweig M, Chmielecki J, Lu X, Bauer TM, et al. Activation of MET via diverse exon 14 splicing alterations occurs in multiple tumor types and confers clinical sensitivity to MET inhibitors. Cancer Discov. 2015;5(8):850-9.

4. Climente-Gonzalez H, Porta-Pardo E, Godzik A, Eyras E. The functional impact of alternative splicing in Cancer. Cell Rep. 2017;20(9):2215-26.

5. Urbanski LM, Leclair N, Anczukow O. Alternative-splicing defects in cancer: splicing regulators and their downstream targets, guiding the way to novel cancer therapeutics. Wiley Interdiscip Rev RNA. 2018;9(4):e1476.

6. Romero-Barrios N, Legascue MF, Benhamed M, Ariel F, Crespi M. Splicing regulation by long noncoding RNAs. Nucleic Acids Res. 2018;46(5):2169-84

7. Martinez-Montiel N, Rosas-Murrieta NH, Anaya Ruiz M, Monjaraz-Guzman E, Martinez-Contreras R. Alternative Splicing as a Target for CancerTreatment. Int J Mol SC. 2018;19(2):504

8. Lee $Y$, Rio DC. Mechanisms and regulation of alternative pre-mRNA splicing. Annu Rev Biochem. 2015;84:291-323.

9. Song $X$, Zeng $Z$, Wei $H$, Wang Z. Alternative splicing in cancers: from aberrant regulation to new therapeutics. Semin Cell Dev Biol. 2018;75:13-22.

10. Kornblihtt AR, Schor IE, Allo M, Dujardin G, Petrillo E, Munoz MJ. Alternative splicing: a pivotal step between eukaryotic transcription and translation. Nat Rev Mol Cell Biol. 2013;14(3):153-65.

11. Busch A, Hertel KJ. Evolution of SR protein and hnRNP splicing regulatory factors. Wiley Interdiscip Rev RNA. 2012;3(1):1-12.

12. Long JC, Caceres JF. The SR protein family of splicing factors: master regulators of gene expression. Biochem J. 2009;417(1):15-27.

13. Han SP, Tang YH, Smith R. Functional diversity of the hnRNPs: past, present and perspectives. Biochem J. 2010;430(3):379-92.

14. Yang J, Hung LH, Licht T, Kostin S, Looso M, Khrameeva E, et al. RBM24 is a major regulator of muscle-specific alternative splicing. Dev Cell. 2014;31(1): 87-99.

15. Tilgner H, Knowles DG, Johnson R, Davis CA, Chakrabortty S, Djebali S, et al. Deep sequencing of subcellular RNA fractions shows splicing to be predominantly co-transcriptional in the human genome but inefficient for IncRNAs. Genome Res. 2012;22(9):1616-25.

16. Pandya-Jones A, Black DL. Co-transcriptional splicing of constitutive and alternative exons. RNA (New York, NY). 2009;15(10):1896-908.

17. Pradeepa MM, Sutherland HG, Ule J, Grimes GR, Bickmore WA. Psip1/Ledg p52 binds methylated histone H3K36 and splicing factors and contributes to the regulation of alternative splicing. PLoS Genet. 2012;8(5):e1002717.

18. Simon JM, Hacker KE, Singh D, Brannon AR, Parker JS, Weiser M, et al. Variation in chromatin accessibility in human kidney cancer links H3K36 methyltransferase loss with widespread RNA processing defects. Genome Res. 2014;24(2):241-50

19. Yoshida K, Ogawa S. Splicing factor mutations and cancer. Wiley Interdiscip Rev RNA. 2014;5(4):445-59.

20. Bonnal SC, Lopez-Oreja I, Valcarcel J. Roles and mechanisms of alternative splicing in cancer - implications for care. Nat Rev Clin Oncol. 2020;17(8):45774.

21. Kim E, llagan JO, Liang Y, Daubner GM, Lee SC, Ramakrishnan A, et al. SRSF2 mutations contribute to Myelodysplasia by mutant-specific effects on exon recognition. Cancer Cell. 2015;27(5):617-30.

22. Wan L, Yu W, Shen E, Sun W, Liu Y, Kong J, et al. SRSF6-regulated alternative splicing that promotes tumour progression offers a therapy target for colorectal cancer. Gut. 2019;68(1):118-29.

23. Kawamura N, Nimura K, Saga K, Ishibashi A, Kitamura K, Nagano H, et al. SF3B2-mediated RNA splicing drives human prostate Cancer progression. Cancer Res. 2019;79(20):5204-17.

24. Jensen MA, Wilkinson JE, Krainer AR. Splicing factor SRSF6 promotes hyperplasia of sensitized skin. Nat Struct Mol Biol. 2014;21(2):189-97.

25. Djebali S, Davis CA, Merkel A, Dobin A, Lassmann T, Mortazavi A, et al. Landscape of transcription in human cells. Nature. 2012:489(7414):101-8. 26. Lu TX, Rothenberg ME. MicroRNA. J Allergy Clin Immunol. 2018;141(4):1202-7.
27. Baek D, Villen J, Shin C, Camargo FD, Gygi SP, Bartel DP. The impact of microRNAs on protein output. Nature. 2008;455(7209):64-71.

28. Mohr AM, Mott JL. Overview of microRNA biology. Semin Liver Dis. 2015; 35(1):3-11.

29. Hombach S, Kretz M. Non-coding RNAs: classification, biology and functioning. Adv Exp Med Biol. 2016:937:3-17.

30. Hinnebusch AG, Ivanov IP, Sonenberg N. Translational control by 5'untranslated regions of eukaryotic mRNAs. Science (New York, NY). 2016; 352(6292):1413-6.

31. Pu M, Chen J, Tao Z, Miao L, Qi X, Wang Y, et al. Regulatory network of miRNA on its target: coordination between transcriptional and posttranscriptional regulation of gene expression. Cell Mol Life Sci. 2019;76(3): $441-51$.

32. Chen LL. Linking Long Noncoding RNA localization and function. Trends Biochem Sci. 2016:41(9):761-72.

33. Akhade VS, Pal D, Kanduri C. Long Noncoding RNA: Genome organization and mechanism of action. Adv Exp Med Biol. 2017:1008:47-74.

34. Ruiz-Orera J, Messeguer X, Subirana JA, Alba MM. Long non-coding RNAs as a source of new peptides. eLife. 2014;3:e03523.

35. Pamudurti NR, Bartok O, Jens M, Ashwal-Fluss R, Stottmeister C, Ruhe L, et al. Translation of CircRNAs. Mol Cell. 2017;66(1):9-21.e7.

36. Yu CY, Kuo HC. The emerging roles and functions of circular RNAs and their generation. J Biomed Sci. 2019;26(1):29.

37. Kristensen LS, Andersen MS, Stagsted LWW, Ebbesen KK, Hansen TB, Kjems J. The biogenesis, biology and characterization of circular RNAs. Nat Rev Genet. 2019;20(11):675-91.

38. Valadkhan S, Gunawardane LS. Role of small nuclear RNAs in eukaryotic gene expression. Essays Biochem. 2013;54:79-90.

39. Yoshino $Y$, Dwivedi $Y$. Non-coding RNAs in psychiatric disorders and suicidal behavior. Front Psychiatry. 2020;11:543893.

40. Bohnsack MT, Sloan KE. Modifications in small nuclear RNAs and their roles in spliceosome assembly and function. Biol Chem. 2018;399(11):1265-76.

41. Dvinge $\mathrm{H}$, Guenthoer J, Porter PL, Bradley RK. RNA components of the spliceosome regulate tissue- and cancer-specific alternative splicing. Genome Res. 2019;29(10):1591-604

42. Dong X, Ding S, Yu M, Niu L, Xue L, Zhao Y, et al. Small nuclear RNAs (U1, U2, U5) in tumor-educated platelets are Downregulated and act as promising biomarkers in lung Cancer. Front Oncol. 2020;10:1627.

43. Lavorgna G, Dahary D, Lehner B, Sorek R, Sanderson CM, Casari G. In search of antisense. Trends Biochem Sci. 2004;29(2):88-94.

44. Villamizar O, Chambers CB, Riberdy JM, Persons DA, Wilber A. Long noncoding RNA Saf and splicing factor 45 increase soluble Fas and resistance to apoptosis. Oncotarget. 2016;7(12):13810-26.

45. Kim R, Emi M, Tanabe K, Uchida Y, Toge T. The role of Fas ligand and transforming growth factor beta in tumor progression: molecular mechanisms of immune privilege via Fas-mediated apoptosis and potential targets for cancer therapy. Cancer. 2004;100(11):2281-91.

46. Xu S, Wang P, Zhang J, Wu H, Sui S, Zhang J, et al. Ai-IncRNA EGOT enhancing autophagy sensitizes paclitaxel cytotoxicity via upregulation of ITPR1 expression by RNA-RNA and RNA-protein interactions in human cancer. Mol Cancer. 2019;18(1):89.

47. Beltran M, Puig I, Pena C, Garcia JM, Alvarez AB, Pena R, et al. A natural antisense transcript regulates Zeb2/Sip1 gene expression during Snail1induced epithelial-mesenchymal transition. Genes Dev. 2008;22(6):756-69.

48. Skryabin BV, Kremerskothen J, Vassilacopoulou D, Disotell TR, Kapitonov W, Jurka J, et al. The BC200 RNA gene and its neural expression are conserved in Anthropoidea (primates). J Mol Evol. 1998;47(6):677-85.

49. Lee EF, Fairlie WD. The Structural Biology of Bcl-xL. Int J Mol Sci. 2019;20(9): 2234.

50. Singh R, Gupta SC, Peng WX, Zhou N, Pochampally R, Atfi A, et al. Regulation of alternative splicing of $\mathrm{BCl}-\mathrm{x}$ by $\mathrm{BC} 200$ contributes to breast cancer pathogenesis. Cell Death Dis. 2016;7(6):e2262.

51. Hossini AM, Eberle J, Fecker LF, Orfanos CE, Geilen CC. Conditional expression of exogenous BCl-X(S) triggers apoptosis in human melanoma cells in vitro and delays growth of melanoma xenografts. FEBS Lett. 2003; 553(3):250-6.

52. Redis RS, Vela LE, Lu W, Ferreira de Oliveira J, Ivan C, Rodriguez-Aguayo C, et al. Allele-specific reprogramming of Cancer metabolism by the Long non-coding RNA CCAT2. Mol Cell. 2016;61(4):520-34.

53. Singh RN, Singh NN. A novel role of U1 SnRNP: splice site selection from a distance. Biochim Biophys Acta Gene Regul Mech. 2019;1862(6):634-42. 
54. Jonas $\mathrm{S}$, Izaurralde $\mathrm{E}$. Towards a molecular understanding of microRNAmediated gene silencing. Nat Rev Genet. 2015;16(7):421-33.

55. Thomson DW, Dinger ME. Endogenous microRNA sponges: evidence and controversy. Nat Rev Genet. 2016;17(5):272-83.

56. Meseguer S, Mudduluru G, Escamilla JM, Allgayer H, Barettino D. MicroRNAs10a and -10b contribute to retinoic acid-induced differentiation of neuroblastoma cells and target the alternative splicing regulatory factor SFRS1 (SF2/ASF). J Biol Chem. 2011;286(6):4150-64.

57. Huang $Y Q$, Ling $X H$, Yuan $R Q$, Chen $Z Y$, Yang $S B$, Huang $H X$, et al. miR30c suppresses prostate cancer survival by targeting the ASF/SF2 splicing factor oncoprotein. Mol Med Rep. 2017;16(3):2431-8.

58. Liu Z, Li W, Pang Y, Zhou Z, Liu S, Cheng K, et al. SF3B4 is regulated by microRNA-133b and promotes cell proliferation and metastasis in hepatocellular carcinoma. EBioMedicine. 2018;38:57-68.

59. Wu H, Sun S, Tu K, Gao Y, Xie B, Krainer AR, et al. A splicing-independent function of SF2/ASF in microRNA processing. Mol Cell. 2010;38(1):67-77.

60. Sokol E, Kedzierska H, Czubaty A, Rybicka B, Rodzik K, Tanski Z, et al. microRNAmediated regulation of splicing factors SRSF1, SRSF2 and hnRNP A1 in context of their alternatively spliced 3'UTRs. Exp Cell Res. 2018;363(2):208-17.

61. Li M, Wu P, Yang Z, Deng S, Ni L, Zhang Y, et al. miR-193a-5p promotes pancreatic cancer cell metastasis through SRSF6-mediated alternative splicing of OGDHL and ECM1. Am J Cancer Res. 2020;10(1):38-59.

62. Boguslawska J, Sokol E, Rybicka B, Czubaty A, Rodzik K, Piekielko-Witkowska A. microRNAs target SRSF7 splicing factor to modulate the expression of osteopontin splice variants in renal cancer cells. Gene. 2016;595(2):142-9.

63. Yoshino H, Enokida H, Chiyomaru T, Tatarano S, Hidaka H, Yamasaki T, et al. Tumor suppressive microRNA-1 mediated novel apoptosis pathways through direct inhibition of splicing factor serine/arginine-rich 9 (SRSF9/SRp30c) in bladder cancer. Biochem Biophys Res Commun. 2012;417(1):588-93.

64. Zhou B, Wang Y, Jiang J, Jiang H, Song J, Han T, et al. The long noncoding RNA colon cancer-associated transcript-1/miR-490 axis regulates gastric cancer cell migration by targeting hnRNPA1. IUBMB Life. 2016;68(3):201-10.

65. Sun Y, Zhao X, Zhou Y, Hu Y. miR-124, miR-137 and miR-340 regulate colorectal cancer growth via inhibition of the Warburg effect. Oncol Rep. 2012;28(4):1346-52.

66. Zhang $\mathrm{M}$, Zhang $\mathrm{H}$, Hong $\mathrm{H}$, Zhang Z. MiR-374b re-sensitizes hepatocellular carcinoma cells to sorafenib therapy by antagonizing PKM2-mediated glycolysis pathway. Am J Cancer Res. 2019;9(4):765-78.

67. Liu J, Bian T, Feng J, Qian L, Zhang J, Jiang D, et al. miR-335 inhibited cell proliferation of lung cancer cells by target Tra2beta. Cancer Sci. 2018;109(2): 289-96.

68. Qian T, Shi S, Xie L, Zhu Y. miR-938 promotes cell proliferation by regulating RBM5 in lung adenocarcinoma cells. Cell biology international. 2019.

69. Dou XQ, Chen XJ, Zhou Q, Wen MX, Zhang SZ, Zhang SQ. miR-335 modulates numb alternative splicing via targeting RBM10 in endometrial cancer. Kaohsiung J Med Sci. 2020;36(3):171-7.

70. Sugiyama T, Taniguchi K, Matsuhashi N, Tajirika T, Futamura M, Takai T, et al. MiR-133b inhibits growth of human gastric cancer cells by silencing pyruvate kinase muscle-splicer polypyrimidine tract-binding protein 1. Cancer Sci. 2016;107(12):1767-75.

71. Teplyuk NM, Uhlmann EJ, Gabriely G, Volfovsky N, Wang Y, Teng J, et al. Therapeutic potential of targeting microRNA-10b in established intracranial glioblastoma: first steps toward the clinic. EMBO Mol Med. 2016;8(3):268-87.

72. Kim EJ, Kim JS, Lee S, Lee H, Yoon JS, Hong JH, et al. QKI, a miR-200 target gene, suppresses epithelial-to-mesenchymal transition and tumor growth. Int J Cancer. 2019;145(6):1585-95.

73. Pillman KA, Phillips CA, Roslan S, Toubia J, Dredge BK, Bert AG, et al. miR200/375 control epithelial plasticity-associated alternative splicing by repressing the RNA-binding protein Quaking. EMBO J. 2018;37(13):e99016.

74. Mukohyama J, Isobe T, Hu Q, Hayashi T, Watanabe T, Maeda M, et al. miR221 targets QKI to enhance the tumorigenic capacity of human colorectal Cancer stem cells. Cancer Res. 2019;79(20):5151-8.

75. Li K, Zhu X, Chen X, Wang X. MicroRNA-27a-3p promotes epithelialmesenchymal transition by targeting NOVA alternative splicing regulator 1 in gastric cancer. Mol Med Rep. 2020;21(3):1615-22.

76. Puppo M, Bucci G, Rossi M, Giovarelli M, Bordo D, Moshiri A, et al. miRNA-mediated KHSRP silencing rewires distinct post-transcriptional programs during TGF-betainduced epithelial-to-Mesenchymal transition. Cell Rep. 2016;16(4):967-78.

77. Fang Z, Zhao J, Xie W, Sun Q, Wang H, Qiao B. LncRNA UCA1 promotes proliferation and cisplatin resistance of oral squamous cell carcinoma by sunppressing miR-184 expression. Cancer Med. 2017;6(12):2897-908.
78. Chen L, Nan A, Zhang N, Jia Y, Li X, Ling Y, et al. Circular RNA 100146 functions as an oncogene through direct binding to miR-361-3p and miR615-5p in non-small cell lung cancer. Mol Cancer. 2019;18(1):13.

79. Tripathi V, Ellis JD, Shen Z, Song DY, Pan Q, Watt AT, et al. The nuclearretained noncoding RNA MALAT1 regulates alternative splicing by modulating SR splicing factor phosphorylation. Mol Cell. 2010;39(6):925-38.

80. Hu ZY, Wang XY, Guo WB, Xie LY, Huang YQ, Liu YP, et al. Long non-coding RNA MALAT1 increases AKAP-9 expression by promoting SRPK1-catalyzed SRSF1 phosphorylation in colorectal cancer cells. Oncotarget. 2016;7(10): 11733-43.

81. Koizumi J, Okamoto Y, Onogi H, Mayeda A, Krainer AR, Hagiwara M. The subcellular localization of SF2/ASF is regulated by direct interaction with SR protein kinases (SRPKs). J Biol Chem. 1999;274(16):11125-31.

82. Stamm S. Regulation of alternative splicing by reversible protein phosphorylation. J Biol Chem. 2008;283(3):1223-7.

83. Xiao SH, Manley JL. Phosphorylation of the ASF/SF2 RS domain affects both protein-protein and protein-RNA interactions and is necessary for splicing. Genes Dev. 1997;11(3):334-44.

84. Misteli T, Caceres JF, Clement JQ, Krainer AR, Wilkinson MF, Spector DL. Serine phosphorylation of SR proteins is required for their recruitment to sites of transcription in vivo. J Cell Biol. 1998;143(2):297-307.

85. Huang A, Zheng H, Wu Z, Chen M, Huang Y. Circular RNA-protein interactions: functions, mechanisms, and identification. Theranostics. 2020; 10(8):3503-17.

86. Zhu LY, Zhu YR, Dai DJ, Wang X, Jin HC. Epigenetic regulation of alternative splicing. Am J Cancer Res. 2018;8(12):2346-58.

87. Zhang Z, Zhou N, Huang J, Ho TT, Zhu Z, Qiu Z, et al. Regulation of androgen receptor splice variant AR3 by PCGEM1. Oncotarget. 2016;7(13):15481-91.

88. Huang GW, Zhang YL, Liao LD, Li EM, Xu LY. Natural antisense transcript TPM1-AS regulates the alternative splicing of tropomyosin I through an interaction with RNA-binding motif protein 4. Int J Biochem Cell Biol. 2017; 90:59-67.

89. Yap K, Mukhina S, Zhang G, Tan JSC, Ong HS, Makeyev EV. A Short Tandem RepeatEnriched RNA Assembles a Nuclear Compartment to Control Alternative Splicing and Promote Cell Survival. Mol Cell. 2018;72(3):525-540.e13.

90. Barbagallo D, Caponnetto A, Brex D, Mirabella F, Barbagallo C, Lauretta G, et al. CircSMARCA5 Regulates VEGFA mRNA Splicing and Angiogenesis in Glioblastoma Multiforme Through the Binding of SRSF1. Cancers (Basel). 2019;11(2):194.

91. Qin M, Wei G, Sun X. Circ-UBR5: An exonic circular RNA and novel small nuclear RNA involved in RNA splicing. Biochem Biophys Res Commun. 2018; 503(2):1027-34.

92. Kong J, Sun W, Li C, Wan L, Wang S, Wu Y, et al. Long non-coding RNA LINC01133 inhibits epithelial-mesenchymal transition and metastasis in colorectal cancer by interacting with SRSF6. Cancer Lett. 2016;380(2):476-84.

93. Sehgal L, Mathur R, Braun FK, Wise JF, Berkova Z, Neelapu S, et al. FASantisense 1 IncRNA and production of soluble versus membrane FAS in Bcell lymphoma. Leukemia. 2014;28(12):2376-87.

94. Pospiech N, Cibis H, Dietrich L, Muller F, Bange T, Hennig S. Identification of novel PANDAR protein interaction partners involved in splicing regulation. Sci Rep. 2018:8(1):2798.

95. Huan $L$, Guo T, Wu Y, Xu L, Huang $S, X u Y$, et al. Hypoxia induced LUCAT1/ PTBP1 axis modulates cancer cell viability and chemotherapy response. Mol Cancer. 2020;19(1):11.

96. Ji Q, Zhang L, Liu X, Zhou L, Wang W, Han Z, et al. Long non-coding RNA MALAT1 promotes tumour growth and metastasis in colorectal cancer through binding to SFPQ and releasing oncogene PTBP2 from SFPQ/PTBP2 complex. Br J Cancer. 2014;111(4):736-48.

97. Ishizuka A, Hasegawa Y, Ishida K, Yanaka K, Nakagawa S. Formation of nuclear bodies by the IncRNA Gomafu-associating proteins Celf3 and SF1. Genes Cells. 2014;19(9):704-21.

98. Rodriguez-Mateo C, Torres B, Gutierrez G, Pintor-Toro JA. Downregulation of Lnc-Spry1 mediates TGF-beta-induced epithelial-mesenchymal transition by transcriptional and posttranscriptional regulatory mechanisms. Cell Death Differ. 2017;24(5):785-97.

99. De Troyer L, Zhao P, Pastor T, Baietti MF, Barra J, Vendramin R, et al. Stressinduced InCRNA LASTR fosters cancer cell fitness by regulating the activity of the U4/U6 recycling factor SART3. Nucleic Acids Res. 2020;48(5):2502-17.

100. Sun F, Chen HG, Li W, Yang X, Wang X, Jiang R, et al. Androgen receptor splice variant AR3 promotes prostate cancer via modulating expression of autocrine/paracrine factors. J Biol Chem. 2014;289(3):1529-39. 
101. Gonzalez I, Munita R, Agirre E, Dittmer TA, Gysling K, Misteli T, et al. A IncRNA regulates alternative splicing via establishment of a splicing-specific chromatin signature. Nat Struct Mol Biol. 2015;22(5):370-6.

102. Amann T, Bataille F, Spruss T, Dettmer K, Wild P, Liedtke C, et al. Reduced expression of fibroblast growth factor receptor $211 \mathrm{lb}$ in hepatocellular carcinoma induces a more aggressive growth. Am J Pathol. 2010;176(3): $1433-42$.

103. Huang JZ, Chen M, Gao XC, Zhu S, Huang H, et al. A Peptide Encoded by a Putative IncRNA HOXB-AS3 Suppresses Colon Cancer Growth. Mol Cell. 2017;68(1):171-184.e6.

104. Long Y, Wang X, Youmans DT, Cech TR. How do IncRNAs regulate transcription? Sci Adv. 2017;3(9):eaao2110.

105. Tang Y, Cheung BB, Atmadibrata B, Marshall GM, Dinger ME, Liu PY, et al. The regulatory role of long noncoding RNAs in cancer. Cancer Lett. 2017; 391:12-9.

106. Zhang XD, Huang GW, Xie YH, He JZ, Guo JC, Xu XE, et al. The interaction of IncRNA EZR-AS1 with SMYD3 maintains overexpression of EZR in ESCC cells. Nucleic Acids Res. 2018;46(4):1793-809.

107. Sims RJ 3rd, Millhouse S, Chen CF, Lewis BA, Erdjument-Bromage H, Tempst $\mathrm{P}$, et al. Recognition of trimethylated histone $\mathrm{H} 3$ lysine 4 facilitates the recruitment of transcription postinitiation factors and pre-mRNA splicing Mol Cell. 2007;28(4):665-76

108. Khan DH, Gonzalez C, Tailor N, Hamedani MK, Leygue E, Davie JR. Dynamic histone acetylation of H3K4me3 nucleosome regulates MCL1 pre-mRNA splicing. J Cell Physiol. 2016;231(10):2196-204.

109. Bae J, Leo CP, Hsu SY, Hsueh AJ. MCL-1S, a splicing variant of the antiapoptotic BCL-2 family member MCL-1, encodes a proapoptotic protein possessing only the BH3 domain. J Biol Chem. 2000;275(33):25255-61.

110. He R, Kidder BL. H3K4 demethylase KDM5B regulates global dynamics of transcription elongation and alternative splicing in embryonic stem cells. Nucleic Acids Res. 2017;45(11):6427-41.

111. Li H, An J, Wu M, Zheng Q, Gui X, Li T, et al. LncRNA HOTAIR promotes human liver cancer stem cell malignant growth through downregulation of SETD2. Oncotarget. 2015;6(29):27847-64.

112. Skucha A, Ebner J, Grebien F. Roles of SETD2 in Leukemia-Transcription, DNA-Damage, and Beyond. Int J Mol Sci. 2019;20(5):1029.

113. Li XW, Shi BY, Yang QL, Wu J, Wu HM, Wang YF, et al. Epigenetic regulation of CDH1 exon 8 alternative splicing in gastric cancer. BMC Cancer. 2015;15:954.

114. Somasundaram S, Forrest ME, Moinova H, Cohen A, Varadan V, LaFramboise T, et al. The DNMT1-associated lincRNA DACOR1 reprograms genome-wide DNA methylation in colon cancer. Clin Epigenetics. 2018;10(1):127.

115. Dor Y, Cedar H. Principles of DNA methylation and their implications for biology and medicine. Lancet (London, England). 2018;392(10149):777-86.

116. Baryshev M, Inashkina I, Salmina K, Huna A, Jackson TR, Erenpreisa J. DNA methylation of the Oct4A enhancers in embryonal carcinoma cells after etoposide treatment is associated with alternative splicing and altered pluripotency in reversibly senescent cells. Cell Cycle (Georgetown, Tex). 2018;17(3):362-6.

117. Liu Y, Zhang YM, Ma FB, Pan SR, Liu BZ. Long noncoding RNA HOXA11-AS promotes gastric cancer cell proliferation and invasion via SRSF1 and functions as a biomarker in gastric cancer. World J Gastroenterol. 2019; 25(22):2763-75.

118. Teplyuk NM, Mollenhauer B, Gabriely G, Giese A, Kim E, Smolsky M, et al. MicroRNAs in cerebrospinal fluid identify glioblastoma and metastatic brain cancers and reflect disease activity. Neuro-oncology. 2012;14(6):689-700.

119. Gao T, Liu X, He B, Nie Z, Zhu C, Zhang P, et al. Exosomal IncRNA $91 \mathrm{H}$ is associated with poor development in colorectal cancer by modifying HNRNPK expression. Cancer Cell Int. 2018;18:11.

120. Wu ZH, Liu CC, Zhou YQ, Hu LN, Guo WJ. OnclncRNA-626 promotes malignancy of gastric cancer via inactivated the p53 pathway through interacting with SRSF1. Am J Cancer Res. 2019;9(10):2249-63.

121. Montero-Conde C, Grana-Castro O, Martin-Serrano G, Martinez-Montes AM, Zarzuela E, Munoz J, et al. Hsa-miR-139-5p is a prognostic thyroid cancer marker involved in HNRNPF-mediated alternative splicing. Int J Cancer. 2020;146(2):521-30.

122. Lee SD, Yu D, Lee DY, Shin HS, Jo JH, Lee YC. Upregulated microRNA-193a$3 p$ is responsible for cisplatin resistance in CD44(+) gastric cancer cells. Cancer Sci. 2019;110(2):662-73.

123. Li D, Wang X, Mei H, Fang E, Ye L, Song H, et al. Long Noncoding RNA pancEts-1 promotes neuroblastoma progression through hnRNPK-mediated beta-catenin stabilization. Cancer Res. 2018;78(5):1169-83.
124. Guo LY, Qin CF, Zou HX, Song MY, Gong ML, Chen C. LncRNA AB073614 promotes the proliferation and inhibits apoptosis of cervical cancer cells by repressing RBM5. Eur Rev Med Pharmacol Sci. 2019;23(6):2374-9.

125. Sun BZ, Ji DG, Feng ZX, Wang Y. Long noncoding RNA SNHG7 represses the expression of RBM5 to strengthen metastasis of hepatocellular carcinoma. Eur Rev Med Pharmacol Sci. 2019;23(13):5699-704.

126. Yang ZT, An F, Hu JD, Zhao WH. Long noncoding RNA AFAP1-AS1 accelerates the proliferation and metastasis of prostate cancer via inhibiting RBM5 expression. Eur Rev Med Pharmacol Sci. 2019;23(8):3284-90.

127. Jiang D, Zhang Y, Yang L, Lu W, Mai L, Guo H, et al. Long noncoding RNA HCG22 suppresses proliferation and metastasis of bladder cancer cells by regulation of PTBP1. J Cell Physiol. 2020;235(2):1711-22.

128. Inamoto $T$, Taniguchi $K$, Takahara K, Iwatsuki A, Takai T, Komura K, et al. Intravesical administration of exogenous microRNA-145 as a therapy for mouse orthotopic human bladder cancer xenograft. Oncotarget. 2015;6(25): 21628-35.

129. Minami K, Taniguchi K, Sugito N, Kuranaga $Y$, Inamoto T, Takahara K, et al. MiR-145 negatively regulates Warburg effect by silencing KLF4 and PTBP1 in bladder cancer cells. Oncotarget. 2017;8(20):33064-77.

130. Takai T, Yoshikawa Y, Inamoto T, Minami K, Taniguchi K, Sugito N, et al. A Novel Combination RNAi toward Warburg Effect by Replacement with miR145 and Silencing of PTBP1 Induces Apoptotic Cell Death in Bladder Cancer Cells. Int J Mol Sci. 2017;18(1).

131. Lv L, Deng H, Li Y, Zhang C, Liu X, Liu Q, et al. The DNA methylationregulated miR-193a-3p dictates the multi-chemoresistance of bladder cancer via repression of SRSF2/PLAU/HIC2 expression. Cell Death Dis. 2014; 5:e1402.

132. Honigberg LA, Smith AM, Sirisawad M, Verner E, Loury D, Chang B, et al. The Bruton tyrosine kinase inhibitor PCl-32765 blocks B-cell activation and is efficacious in models of autoimmune disease and B-cell malignancy. Proc Natl Acad Sci U S A. 2010;107(29):13075-80.

133. Sander S, Bullinger L, Klapproth K, Fiedler K, Kestler HA, Barth TF, et al. MYC stimulates $\mathrm{EZH} 2$ expression by repression of its negative regulator miR-26a. Blood. 2008;112(10):4202-12.

134. Otsuka K, Yamamoto Y, Ochiya T. Regulatory role of resveratrol, a microRNAcontrolling compound, in HNRNPA1 expression, which is associated with poor prognosis in breast cancer. Oncotarget. 2018;9(37):24718-30.

135. Kumar A, Rimando AM, Levenson AS. Resveratrol and pterostilbene as a microRNA-mediated chemopreventive and therapeutic strategy in prostate cancer. Ann N Y Acad Sci. 2017;1403(1):15-26.

136. Rauf A, Imran M, Butt MS, Nadeem M, Peters DG, Mubarak MS. Resveratrol as an anti-cancer agent: a review. Crit Rev Food Sci Nutr. 2018;58(9):1428-47.

137. Gabriely G, Yi M, Narayan RS, Niers JM, Wurdinger T, Imitola J, et al. Human glioma growth is controlled by microRNA-10b. Cancer Res. 2011;71(10): 3563-72.

138. Antonarakis ES, Lu C, Wang H, Luber B, Nakazawa M, Roeser JC, et al. AR-V7 and resistance to enzalutamide and abiraterone in prostate cancer. N Engl J Med. 2014;371(11):1028-38.

139. Mullard A. Small molecules against RNA targets attract big backers. Nat Rev Drug Discov. 2017;16(12):813-5.

140. Bonetta L. RNA-based therapeutics: ready for delivery? Cell. 2009;136(4):581-4.

141. Vasan N, Baselga J, Hyman DM. A view on drug resistance in cancer. Nature. 2019;575(7782):299-309.

\section{Publisher's Note}

Springer Nature remains neutral with regard to jurisdictional claims in published maps and institutional affiliations.

Ready to submit your research? Choose BMC and benefit from:

- fast, convenient online submission

- thorough peer review by experienced researchers in your field

- rapid publication on acceptance

- support for research data, including large and complex data types

- gold Open Access which fosters wider collaboration and increased citations

- maximum visibility for your research: over $100 \mathrm{M}$ website views per year

At $\mathrm{BMC}$, research is always in progress.

Learn more biomedcentral.com/submissions 